\title{
Phytochemical Study and Antioxidant Activity of Some Anti-Diabetic Plants in the Wilaya of Mascara
}

\section{Karima O*, Righi S, Belhocin A, Mekness A, Meddah B and Tirtouil A}

Laboratory of Bioconversion, Microbiological engineering and safety, Faculty of Sciences, Department of Biology, University of Mascara, Algeria

*Corresponding author: Ould Yerou Karima, Laboratory of Bioconversion, Microbiological engineering and safety, Faculty of Sciences, Department of Biology, University of Mascara, Algeria, Tel: +989142217299; E-mail: mhanine11@yahoo.fr

Received date: January 27, 2018; Accepted date March 6, 2018; Published date: March 9, 2018

Copyright: (c) 2018 Karima O, et al. This is an open-access article distributed under the terms of the Creative Commons Attribution License, which permits unrestricted use, distribution, and reproduction in any medium, provided the original author and source are credited.

\begin{abstract}
An ethno botanical survey of 40 individuals in the Wilaya of Mascara identified 40 medicinal plants used for the treatment of diabetes mellitus. Among these plants, Malva sylvestris, Olea Europea sylvestris, Citrus aurantium have been selected. The objective of our work is the phytochemical study and the antioxidant activity of the 3 plants selected. The raw methanolic extracts of Malva sylvestris and their stems, Olea europea sylvestris and Citrus aurantium were obtained by the extraction method maceration. The quantitative determination of total polyphenols by the Folin Ciocaltieu method and the flavonoids in the presence of $\mathrm{AlCl}_{3}$, the total polyphenol content in Malva sylvestris and their stems, Olea europea sylvestris and Citrus aurantium represents $556.33 \mu \mathrm{g} \mathrm{EAG/g} \mathrm{MS}$ and $443.33 \mathrm{ug}$ EAG/G Ms; $557.66 \mathrm{~g}$ EAG/g Ms $447.77 \mu \mathrm{g}$ EAG/gMS. The content of flavonoids is $1032.33 \mu \mathrm{g}$ EQer/g Ms $898.66 \mathrm{ug}$ EQer/g Ms 894.33, $\mathrm{gg}$ EQer/g Ms $1428.33 \mu \mathrm{gEQer} / \mathrm{g} \mathrm{MS}$. Antioxidant activity of the extracts prepared was measured by two methods. The first is the use of free radical 1,1-diphenyl-2-picrylhydrazyl (DPPH) and the second reducing power of FRAP iron. These methods show that these plants have good antioxidant activity.
\end{abstract}

Keywords: Olea Europea Malva sylvestris, Citrus aurantium; Total polyphenols; Flavonoids; Antioxidant activity; Diabetes sweetened

\section{Introduction}

Diabetes mellitus is considered one of the plagues of the third millennium. The ethno pharmacological approach is of great importance in this field. It enables the identification of anti-diabetic remedies and the establishment of a database of medicinal plants in order to preserve an ancestral knowledge based essentially on an oral tradition. Malva sylvestis family of Malvace; Olea europea family of Oleaceae and Citrus aurantium family of Rutaceae, these three plants are rich in secondary metabolites and are used to treat sugar diabetes.

\section{Materials}

\section{Vegetable marshes}

On the basis of the results of the ethno pharmacological survey and the bibliographic data, we had selected three medicinal plants on which our experimental study was based they are:
1. Olea europaea sylvestris
2. Citrus aurantruim
3. Malva sylvestris

\section{Methods}

\section{Preparation of the methanol extract}

After collection, the plant material is thoroughly cleaned, washed with tap water and then in distilled water. Then wiped and dried in a ventilated and cool place and away from the sun. After drying the plants are crushed.

The raw plant extract is obtained by maceration, which consists in leaving the powder of the plant material in prolonged contact with a solvent (methanol). The separation is by filtration. It is commonly used in the extraction of terpenes, alkaloids, flavonoids, fatty acids, amines.

The vegetable powder (Citrus aurantirium, Olea Europea sylvestris, Malva sylvestris) is macerated for 24 hours at ambient temperature in a methanol-water mixture $(80 / 20, \mathrm{~V} / \mathrm{V})$. The extraction is repeated 3 times with renewal of the solvent. The macerates are combined and filtered on filter paper. The solvent is removed from the filtrate under vacuum at $45^{\circ} \mathrm{C}$ using a Rota vapor.

\section{Determination of total phenols}

In a test tube, a volume of $100 \mu \mathrm{l}$ of crude plant extract is introduced with $500 \mu \mathrm{l}$ of the folate-Ciocalteu reagent $(1 \mathrm{~N})$ after $4 \mathrm{~min} .400 \mu \mathrm{l}$ of sodium carbonate $\mathrm{Na}_{2} \mathrm{CO}_{3}(20 \%)$ are added. The whole is incubated an ambient temperature for 1 hour $30 \mathrm{~min}$. The reading is performed against a blank without extract using a spectrophotometer at $760 \mathrm{~nm}$.

\section{Preparation of the calibration curve}

A calibration curve is carried out in parallel under the same operating conditions using gallic acid as a positive control.

The total polyphenol content of the extracts of the plants studied is expressed in milligrams (mg) equivalent of Gallic acid per $100 \mathrm{~g}$ of the dry plant material (mg EC/100 g).

\section{Expression of results}

The total polyphenol content in our extracts was calculated from a linear calibration curve $(y=a x+b)$ established with precise Gallic acid 
Citation: Karima O, Righi S, Belhocin A, Mekness A, Meddah B, et al. (2018) Phytochemical Study and Antioxidant Activity of Some Anti-

Page 2 of 5

concentrations as the reference standard under the same conditions as the sample.

\section{Determination of flavonoids by the alumium trichloride method}

Principle: The quantification of the flavonoids was carried out by a method based on the formation of complexes between the phenolic compounds and the aluminum trichloride. The complexes produced are of yellow color absorbing in the visible at $510 \mathrm{~nm}$ [1].

Procedure: $500 \mu \mathrm{l}$ of the sample extract is introduced into test tubes. Mixed with $150 \mu \mathrm{l}$ of distilled water followed by $150 \mu \mathrm{l}$ of $5 \%$ sodium nitrite $\left(\mathrm{NaNO}_{2}\right)$. Mix and leave to act for 5 minutes. After addition, $150 \mu \mathrm{l}$ of $10 \%(\mathrm{w} / \mathrm{v})$ aluminum Trichloride $\left(\mathrm{AlCl}_{3}\right)$ is added to the mixture. After 6 min incubation at room temperature

$150 \mu \mathrm{l}$ of $\mathrm{NaOH}(1 \mathrm{M})$ added immediately the mixture is thoroughly stirred to homogenize the contents. The absorbance of the pinkishcolored solution is determined at $510 \mathrm{~nm}$ against a blank.

Preparation of the calibration curve: A standard range is established separately with quercitrin (1\%) to calculate the concentration of flavonoids in each extract. The results of the assay are expressed in milligrams of quercitrin equivalent per gram total dry matter (MST).

\section{Tests, In-vitro, of antioxidant activity}

\section{Method DPPH (2,2'-diphenyl-1-picrylhydrazyl)}

Principle: The antiradical activity of the polyphenolic compounds contained in the extracts prepared is evaluated by measuring their capacities to trap the free radical DPPH (2,2'-diphenyl-1pyridylhydrazyl). Its dark violet color turns yellow when it is reduced (captured by Products tested) [2].

Procedure: Prepare a dilution series containing 5 tubes the mother solution added in $1110 \mathrm{ml}$ of methanol, $10 \mathrm{mg}$ of methanol sample the remaining 4 tubes contains only $5 \mathrm{ml}$ of methanol in each tube.

- Preparation of the blank: $750 \mu$ l of methanol, DPPH $1.5 \mathrm{ml}$

- For each tube, 3 tests (repeat): $750 \mu \mathrm{l}$ of sample, $1.5 \mathrm{ml}$ of DPPH.

Expression of results: $\%$ de piegeage $=[(\mathrm{A} 1-\mathrm{A} 2) / \mathrm{A} 1] \times 100$

Where A1 is the absorbance of the control (DPPH solution without extract) white and A2 is the absorbance in the presence of extract.

Each test was repeated three times, the results were presented by the mean of the three tests.

Calculation of $\mathrm{IC}_{50}: \mathrm{IC}_{50}$ or $50 \%$ inhibitory concentration (also called $\mathrm{EC}_{50}$ for Efficient concentration 50), is the concentration of the test sample required to reduce $50 \%$ of the $\mathrm{DPPH}$ radical. The $\mathrm{IC}_{50} \mathrm{~s}$ are calculated graphically by the linear regressions of the graphs plotted, percent inhibition as a function of different concentrations of the fractions tested [3].

\section{Testing the Antioxidant Power by Reducing Iron (FRAP)}

Principle: The evaluation is based on the reduction reaction of (Fe ${ }^{+3}$ ) present in the potassium ferrocyanide complex in $\left(\mathrm{Fe}^{+2}\right)$, the reaction is revealed by the yellow color change of ferric iron $\left(\mathrm{Fe}^{+3}\right)$ in color Blue green of ferrous iron $\left(\mathrm{Fe}^{+2}\right)$, and the intensity of this staining is measured by spectrophotometer at $700 \mathrm{~nm}[4]$
Procedure: Prepare a dilution series containing 5 tubes stock solution; Added to the tube $10 \mathrm{ml}$ of methanol, $10 \mathrm{mg}$ of sample, and the remaining 4 tubes contained only $5 \mathrm{ml}$ of methanol in each tube

1. White: $1.25 \mathrm{ml}$ of phosphate buffer solution 1.25 , potassium cyanide, $500 \mu \mathrm{l}$ of methanol

2. For each tube, 3 tests were carried out $1.25 \mathrm{ml}$ of phosphate buffer, $1.25 \mathrm{ml}$ of potassium hexoferrocyanide and $500 \mu \mathrm{l}$ of sample.

3. Homogenization and incubation $30 \mathrm{~min}$ at $50^{\circ} \mathrm{C}$.

4. Add $1.25 \mathrm{ml}$ of trichloroacetic acid to $10 \%$

5. Centrifugation $3000 / 10 \mathrm{~min}$

6. Retrieve the on nagent

7. Add $1.25 \mu$ of supernatant,

8. $1.25 \mu \mathrm{H} \mathrm{H}_{2} \mathrm{O}$

9. $250 \mu \mathrm{l}$ of $\mathrm{Fe}_{2} \mathrm{Cl}_{3}$

10. Mix and read the absorbance at $700 \mathrm{~nm}$.

Expression of results: To explore the results obtained, the most common way used by the majority of the authors is to plot the graphs of the absorbance obtained according to the different concentrations used. The increase in absorbance corresponds to an increase in the reducing power of the fractions tested.

\section{Results}

\section{Total phenol contents}

The polyphenol content was estimated using the Folin-Ciocalteu colorimetric method. Olea europea and Malva sylvestris were found to be rich in polyphenols $(557,66 \mu \mathrm{g}$ of EAG/plant and 556, 33), while the levels of Citrus aurantium and the stems of Malva sylvestris were lower than the other (477, 77 and 443, $33 \mu \mathrm{g}$ EAG/plant) respectively. The results show that phenolic compounds are abundant in the studied plants. The high content of polyphenols in the hydromethanol extract is related to the high solubility of phenols in polar solvents [5].

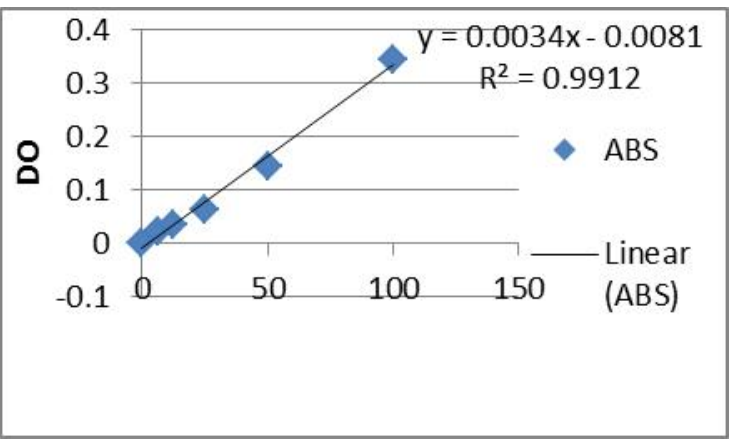

Figure 1: Gallic acid calibration curve.

Faten et al. carried out quantitative measurements of the methanol extract of the olive leaves of two chemlali and nebemel varieties in Tunisia, showing that the total polyphenol content of the chemlali leaves is the Neb jmel variety. Now, our harvest of the leaves of the wild olive was made in the month of March. This confirms that the maximum of the total polyphenols was obtained in the terminal phase 
Citation: Karima O, Righi S, Belhocin A, Mekness A, Meddah B, et al. (2018) Phytochemical Study and Antioxidant Activity of Some Anti-

Page 3 of 5

of leaf growth, i.e the month of March, showing the poverty of our variety in total polyphenols. This difference in content may also depend on the varietal profile (eg. sylvestris) and the geographical area, so the variation in polyphenol contents seems to be related to the olivegrowing area [6,7] (Figures 1 and 2).

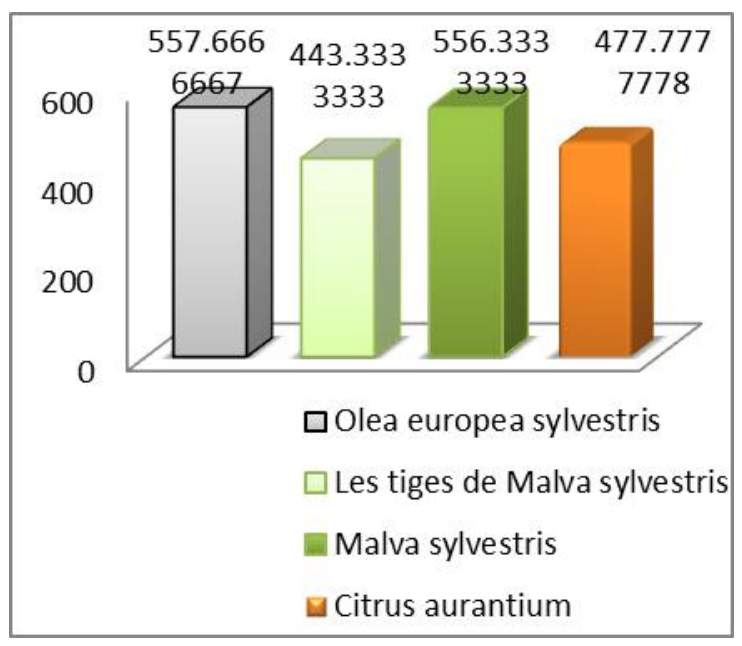

Figure 2: Polyphenol contents in $\mu \mathrm{g}$ EAG / g plant Discussion.

\section{The flavonoid content}

The main property initially recognized for flavonoids are to be "vein-active", that is to say, capable of reducing the permeability of the blood capillaries and of strengthening them [8]

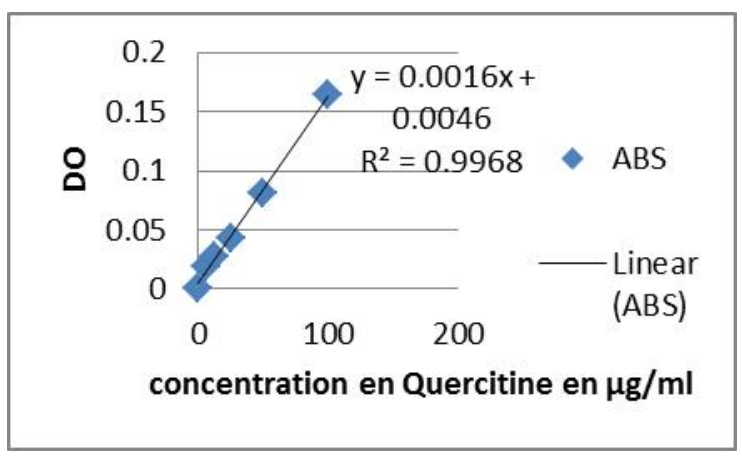

Figure 3: Calibration curve for Quercitine.

The aluminum trichloride method [9] is used to quantify flavonoids in methanol extracts of three plants

A quercetin calibration curve. For this purpose, measurements of densities for each extract were made at $510 \mathrm{~nm}$ for flavonoids. The quantities of the corresponding flavonoids were reported in gram equivalent of the standard used and determined by the following equation: $y=0.001 x+0.004$ from Figures 3 and 4 .

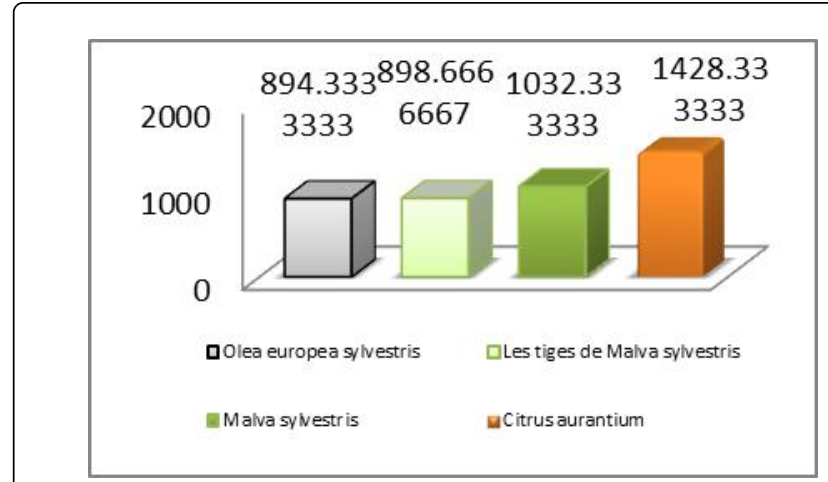

Figure 4: the flavonoid contents in $\mu \mathrm{g} \mathrm{EQ} / \mathrm{g}$ of the extract.

\section{Discussion}

The results, presented in the figure, show that the total flavonoid contents vary considerably between the different plants. The great distinction between the parts studied appears at the level of the wealth of some and the poverty of other Citrus auruntium records a maximum of flavonoids (1428, $33 \mu \mathrm{g} \mathrm{EQ/g}$ on average). While the other plants Malva sylvestris, their stem and Olea europea sylvestris contain levels 1028, 33, 898,66 and 894,33 $\mu \mathrm{g} \mathrm{EQ} / \mathrm{g}$ on average, respectively.

Flavonoids are endowed with hypoglycaemic and antidiabetic properties according to the results of several works carried out [10]. Several mechanisms are attributed to flavonoids for this activity. According to these authors [11], flavonoids prevent diabetes by inhibiting alkalosis reductase. In addition, several studies have shown that the consumption of flavonoid-rich foods is inversely correlated with the risk of developing cardiovascular diseases $[12,13]$.

\section{Antioxidant activity}

DPPH Results: From these results, it can be seen that the percentage of inhibition of the free radical increases with increasing concentration. The levels of DPPH inhibition recorded in the presence of the various extracts are lower than those of ascorbic acid.

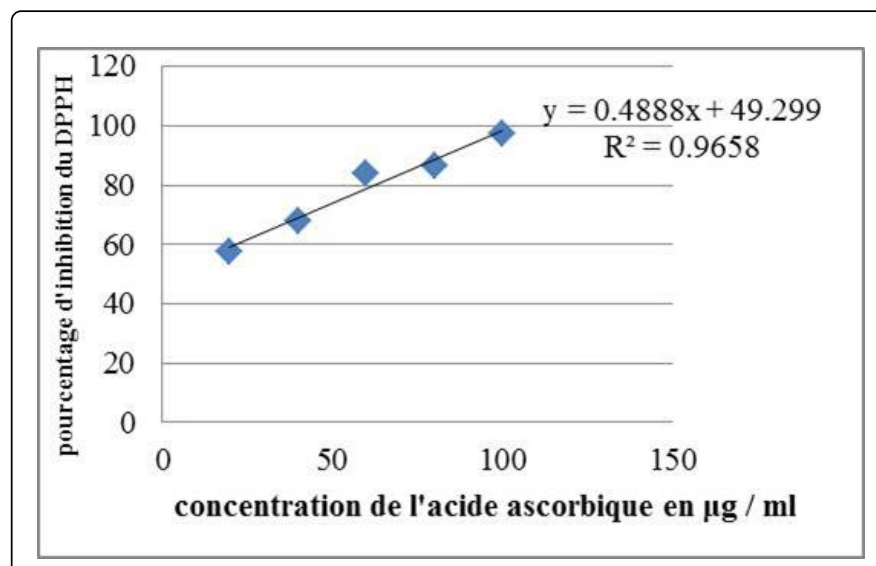

Figure 5: Anti-radical activity of ascorbic acid by the DPPH test. 
Citation: Karima O, Righi S, Belhocin A, Mekness A, Meddah B, et al. (2018) Phytochemical Study and Antioxidant Activity of Some Anti-

Page 4 of 5

The anti-radical activity is carried out by the method of the 2, 2diphenyl-1-picrylhydrazyl radical (DPPH) which is a method frequently used for its simplicity. This method is based on the reduction of an alcoholic solution of DPPH in the presence of an antioxidant which gives hydrogen or an electron, the non-radical form DPPH-H is formed. The inhibition of the discoloration of the DPPH radical is in function of the concentration of the different extracts used and of the control (reference antioxidant) $(\mu \mathrm{g} / \mathrm{ml})$ (Figures 5 and 6$)$.

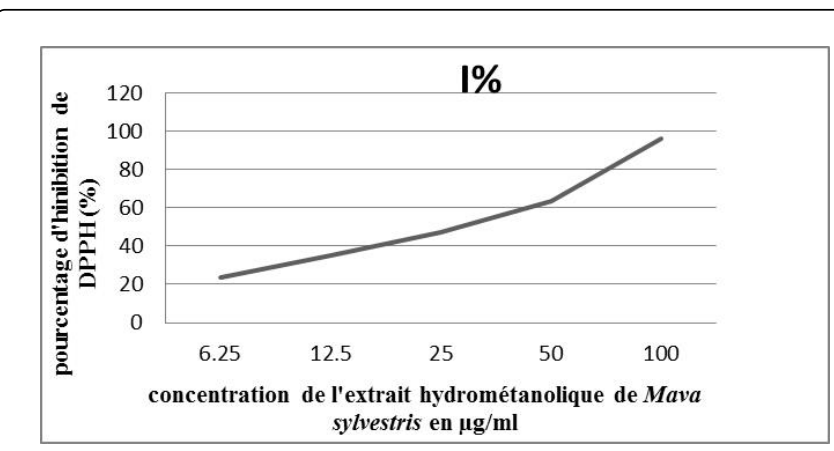

Figure 6: Anti-free radical activity of the hydromethanolic extract of Malva sylvestris by the DPPH test.

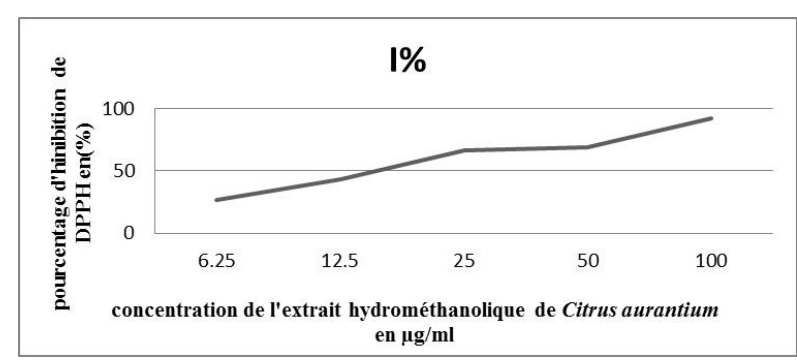

Figure 7: Anti-radical activity of the hydromethanolic extract of Citrus aurantium by the DPPH test.

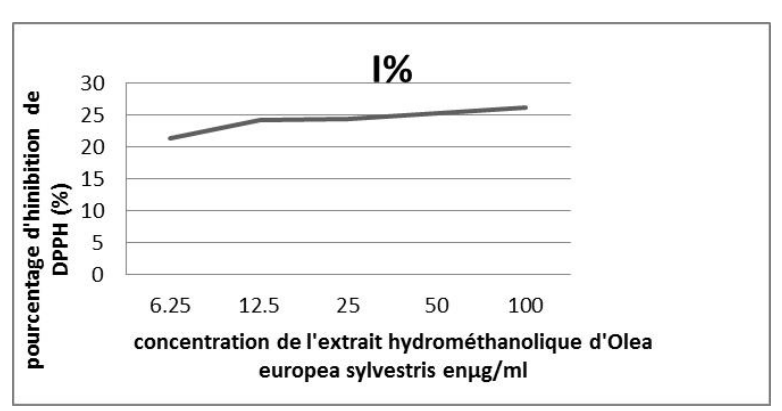

Figure 8: Anti-free radical activity of the hydromethanol extract of Olea europea sylvestris by the DPPH test.

The antioxidant activity of the extracts is expressed as $\mathrm{IC}_{50}$, this parameter has been used by several groups of researchers to present their results [1], it defines the effective substrate concentration which causes $50 \%$ loss of Activity of the DPPH radical (Color). These $\mathrm{IC}_{50} \mathrm{~S}$ are determined from the graphs whose abscissa represents the concentration of the crude extract and the ordered the antioxidant activity in percentage (Figures 7 and 8).

Results of the Reducing Power of Iron: The reduction power of the methanol extracts of the studied plants is determined according to the method $[14,15]$. The reading of the absorbance is made at $700 \mathrm{~nm}$ the results are presented in the following Figure 9.

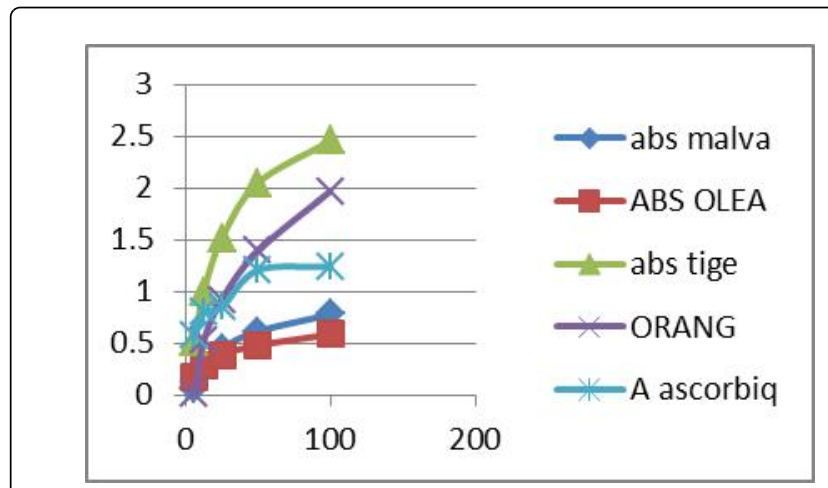

Figure 9: Curve represents reduction of iron deferent extracts.

The iron-reducing power of Malva sylvestris and Citrus aurantium stems is elevated by ascorbic acid intake. The crude extract of these plants is composed of several active phenolic substances. It is assumed that the stems and Citrus aurantium have a synergy between the secondary metabolite deferent. This is for calculating the reduction of iron is high in these plants can be determined from Table 1.

\begin{tabular}{|l|l|}
\hline The extracts & $\mathrm{EC}_{50}(\boldsymbol{\mu g} / \mathbf{m l})$ \\
\hline Acide ascorbique & $14,54,91,803$ \\
\hline Olea europea sylvestris & $41,68,45,329$ \\
\hline Malva sylvestris & $34,35,19,782$ \\
\hline Tige de Malva sylvestris & $23,02,13,465$ \\
\hline
\end{tabular}

Table 1: The $\mathrm{EC}_{50}$ values of the extracts of the studied plants.

The antioxidant activity generally depends on the number and the position of the hydroxyl groups with respect to the functional carboxyl groups. The structure of phenolic compounds is a determining factor in their trapping of free radicals which are pathogens in many diseases. Some of these compounds are capable of chelating iron, and therefore reduce its excess. For this, we evaluated the antioxidant activity of the extracts by the FRAP iron reduction technique, which represents a significant indicator of the antioxidant power of plants. The results show that the reducing capacity of the hydro methanol extracts is higher.

The DPPH radical method used in this study is a common procedure in which the antioxidant activity of the sample studied is estimated by the degree of discoloration of the DPPH solution. This violet chromogenic is easy to use, has high sensitivity, allows rapid analysis of the antioxidant activity of a large number of samples and gives reproducible results $[16,17]$ 
Citation: Karima O, Righi S, Belhocin A, Mekness A, Meddah B, et al. (2018) Phytochemical Study and Antioxidant Activity of Some AntiDiabetic Plants in the Wilaya of Mascara. J Antimicrob Agents 4: 1000165. doi:10.4172/2472-1212.1000165

Page 5 of 5

\section{Conclusion}

The present work focused on the phytochemical study and the antioxidant activity of the raw extracts prepared by maceration of the three medicinal plants belongs to the family of malvaceae, oleaceae, rutaceae of the Wilaya of Mascara thanks to their therapeutic properties (treating diabetes Sweetened). Colorimetric assays showed high concentrations of total polyphenols, flavonoids; the anti-radical potential of the extracts was determined by the methods FRAP and $\mathrm{DPPH}$, the results of which show that the extracts possess a good activity.

\section{References}

1. Allali H, Benmehdi H, Dib MA, Tabti B, Ghalem S, et al. (2008) Phytotherapy of diabetes in West Algeria. Asian J Chemis 20: 2701-2710.

2. Baccouri B, Zarrouk W, Krichene D, Nouairi I, Ben Youssef N, et al. (2004) Influence of fruit ripening and crop yield on chemical properties of virgin olive oils from seven selected Oleasters (Olea europaea L.). J Agro 6: 388-396.

3. Rotondi A, Bendini A, Cerretani L, Mari M, Lercker G, et al. (2004) Effect of olive ripening degree on the oxidative stability and organoleptic properties of cv. nostrana di brisighella extra virgin olive oil. J Food Agric Env 2: 3649-3654.

4. Bruneton J (1999) Pharmacognosie, phytochimie, plantes médicinales Ed. mdicales internationals editions technique \& documentation, Cachan. P. 647-673.

5. Dehpeur M A, Ibrahimzadeh N, Fazel NS, Mohammad NS (2009) Antioxidant activity of the methanol extract of Ferula assafoetida and its essential oil composition. Grasas Y Aceites 60: 405-412.

6. Brahmi F, Mechri B, Dhibi M, Hammami M (2013) Variations in phenolic compounds and antiradical scavenging activityof Olea europaea leaves and fruits extracts collected in two different seasons. Indust Crops Prod 49: 256-264.

7. Ghedadba N, Hambaba L, Aberkane MC, Oueld-Mokhtar SM, Fercha N, et al. (2014)

Evaluation of in vitro haemostatic activity of the aqueous extract of Marrubium vulgare L. leaves. Algerian J Natural Prod 2: 64-74.

8. Guerci B, Bohme P, Schwartz AK, Zannad F, Drouin P (2001) Endothelial dysfunction and type 2 diabetes. Diabetes Metab 27: 436-447.

9. Hollman PCH (2001) Evidence for health benefits of plant phenols : Local or systemic effects? J Sci Food Agricul 81: 842-852.

10. Huang CL, Sumpio BE (2008) Olive oil, the Mediterranean diet, and cardiovascular health. J Am Coll Surg 207: 407-416.

11. Pietta P (2000) Flavonoids as antioxidants. J Natural Products 63: 1035-1042.

12. Pokorny JN, Yanishlieva N, Gordon MH (2001) Antioxidant in food: Practical applications. Woodhead publishing limited, Cambridge, England.

13. Raccah D (2004) Epidemiology and physiopathology of degenerative complications of diabetes mellitus. EMC-Endocrinologie 1: 29-42.

14. Topçu G, Ay M, Bilici A, Sarıkurkcu C, Ozturk, et al. (2007) A new flavones from antioxidant extracts of Pistacia terebinthus. Food Chemis 103: 816-822.

15. Yildirim A, Mavi A, Kara AA (2001)Determination of antioxidant and antimicrobial activities of Rumex crispus L. extracts. J Agricult Food Chem 49: 4083-4089.

16. Rangaee S, Abdel-Hal ESM, Noaman K (2006) Antioxidant activity and nutrient composition of selected cereals for food use. Food Chem 98: 32-38.

17. Tringali C (2001) Bioactive compounds from natural sources: Isolation characterization and biological properties, University of Catania, Italy. Taylor \& Francis. 36: 339-367. 